\title{
Simulation in emergency nursing education: An integrative review
}

\author{
Caio Guilherme S. Bias ${ }^{1}$, Lorene S. Agostinho ${ }^{1}$, Roberta P. Coutinho ${ }^{1}$, Genesis de S. Barbosa ${ }^{* 1,2}$ \\ ${ }^{1}$ Nursing and Midwifery Undergraduate Course, Campus UFRJ-Macae, Macae, Brazil \\ ${ }^{2}$ School of Nursing, University of Sao Paulo, The Brazilian Centre for Evidence-based Healthcare: an Affiliate Center of the \\ Joanna Briggs Institute. Sao Paulo, Brazil
}

Received: April 6, 2016

DOI: $10.5430 /$ jnep.v6n12p12
Accepted: June 7, $2016 \quad$ Online Published: July 18, 2016

URL: http://dx.doi.org/10.5430/jnep.v6n12p12

\begin{abstract}
Introduction: The growing development of technological resources has allowed simulations to be increasingly used in nursing education. Aim: assessing the scientific literature on the use of simulations in emergency nursing education.

Methods: Integrative literature review conducted in databases such as LILACS, MEDLINE, ERIC, and CINAHL, including full-text articles published in English, Portuguese or in Spanish, between 2005 and 2015.

Results: After applying the inclusion and exclusion criteria, the current study selected six primary studies supporting three categories, namely: developing skills and assuredness to work in emergencies; types of simulation used in emergency training; and the impact of simulation on self-confidence and on satisfaction.

Conclusions: Simulation is a satisfactory teaching methodology, which shows positive effects on the responses to emergencies, and it contributes to the participants' assuredness and to the improvement of their skills and self-confidence.
\end{abstract}

Key Words: Nursing, Simulation, Nursing education, Emergencies

\section{INTRODUCTION}

Nurses faced with situations such as serious injuries, terminally ill patients, or abandonment situations are exposed to anxiety and suffering reactions in the course of their professional practice. These variables are maximized when students begin practice field, since sometimes they have little contact with critical situations prior to graduation. ${ }^{[1]}$ Often, when there is no good correlation between theory and practice and, consequently, no development of critical reasoning, students may have negative feelings towards clinical practice, namely: insecurity, frustration, guilt, helplessness, sadness or depreciation. ${ }^{[1-3]}$

Students must have increased contact with extreme medical conditions before they are introduced to the practice in order to diminish their negative feelings towards it and to optimize their performance. ${ }^{[1,3]}$ Although, the limited duration of clinical practices affect the opportunities of students in clinical experience with real patients. ${ }^{[4]}$ Thus, the use of simulations as an educational tool is becoming increasingly prevalent in nursing education. ${ }^{[5]}$

The simulation is an attempt to mimic the characteristics of a particular clinical experience as a way to better understand and manage it. This technique uses artificial environments and simulates real situations in order to practice, learn, evaluate, test or improve the understanding of systems or human actions. $^{[4]}$

\footnotetext{
*Correspondence: Genesis de S. Barbosa; Email: genesis@ufrj.br; Address: Avenida Aloisio da Silva Gomes, n.50 - Granja dos Cavaleiros, Macaé - RJ, Brazil.
} 
The nursing practice shows records about the use of pads to train intramuscular medication administration and of rolledup towels to train venipuncture procedures. However, technological innovations and the development of new tools provided modern simulators to low-, medium- and high-fidelity scenarios. ${ }^{[6]}$

The low-fidelity simulator is a model of external anatomy similar to that of humans, and it may represent a full or partial body. This simulator allows making coarse movements in the major joints and does not show any type of response to the performed interventions. It is mainly indicated to learn specific skills such as venipuncture, nasogastric probing, among others. ${ }^{[6]}$

The medium-fidelity simulator goes beyond the anatomical settings. It shows breathing and heart sounds, and it allows monitoring the electrocardiogram tracing and searching for some pulses (usually central pulses). It may also have some pre-recorded sounds (cough, vomiting, moaning, among others), which are reproduced under the command of the teacher running the simulator. This simulator is indicated in the learning of specific skills and in the composition of simple clinical practice scenarios. ${ }^{[6]}$

On the other hand, the high-fidelity simulator is a manikin anatomically and physiologically similar to the human body. It is managed by the software that controls the physiological responses and enables several signals such as respiratory movements and the blink of an eye. In addition, it allows evaluating different vital parameters-such as the auscultation of respiratory, cardiac and bowel sounds-as well as evaluating some data on the skin-such as the capillary perfusion time, cyanosis, and diaphoresis, among others. It is indicated in the composition of more complex scenarios; however, it is expensive and its maintenance requires specialized professionals. ${ }^{[6]}$

The simulations may lead to several advantages to nursing education, such as boosting the critical thinking, helping teamwork development, helping the recognition of signs and symptoms beyond therapy outcomes, encouraging selfconfidence and reducing insecurity; thus, they improve these professionals' psychological well-being. ${ }^{[7]}$

Simulations are an education tool to health professionals and they may be used as an alternative to learn the theoretical content and to correlate it with the practice. Thereby, they open new paths in areas involving the direct contact with the patient and pressure over the trainees such as the emergency critical care unit. Thus, the clinical practice simulations may help developing students' ability to control factors that could initially affect their performance with a patient or with a real situation, as well as to provide them subsidies for a positive Published by Sciedu Press and confident performance. ${ }^{[8,9]}$

The complexity involving emergency situations and everything about them requires health professionals to have skills that must be properly developed during graduation, namely: self-confidence and training to deal with their occurrence. ${ }^{[10]}$

The lack of contact or opportunities to act in emergencies during training hinders the development of the skills students need in order to perform objectively, with effective, rapid and imperative interventions within this context. The simulation allows training the skills students need to develop in order to act fruitfully in complex emergency scenarios, which require the action of highly trained professionals. ${ }^{[5,10]}$

\section{Aim}

The aim of the current study is to analyze the scientific literature about the use of simulation in emergency nursing education.

\section{Methods}

This is an integrative literature review. This research method aims at systematically and orderly performing the search, the critical evaluation and the synthesis of published studies about a given topic or issue. This search method also shows knowledge gaps that need to be fulfilled with new studies. ${ }^{[11]}$

The current study comprises the following stages: development of guiding questions such as "How are simulations used in emergency nursing education? What are the types of adopted simulations?"; search or sampling of the literature; data collection; critical analysis of results; discussion about the results; and integrative review presentation. ${ }^{[12]}$

The search was done between July and August 2015 in electronic databases such as the Latin American and Caribbean Health Sciences Literature (LILACS), the Medical Literature Analysis and Retrieval System Online (MEDLINE), the Education Resources Information Center (ERIC) and the Cumulative Index to Nursing and Allied Health Literature (CINAHL). The following descriptors were used: "Simulation", "Education" and "Emergency Nursing" as well as their Portuguese and Spanish versions. In addition, the Boolean expressions "AND" and "OR" were adopted in order to cross and recover the articles. The article selection paths can be seen in Figure 1.

The following inclusion criteria were defined to select the articles: studies available in full text, written in English, Spanish or Portuguese, and published between 2005 and 2015. Opinion studies, abstracts, theses, dissertations, or articles written in other languages were excluded from the current study. 


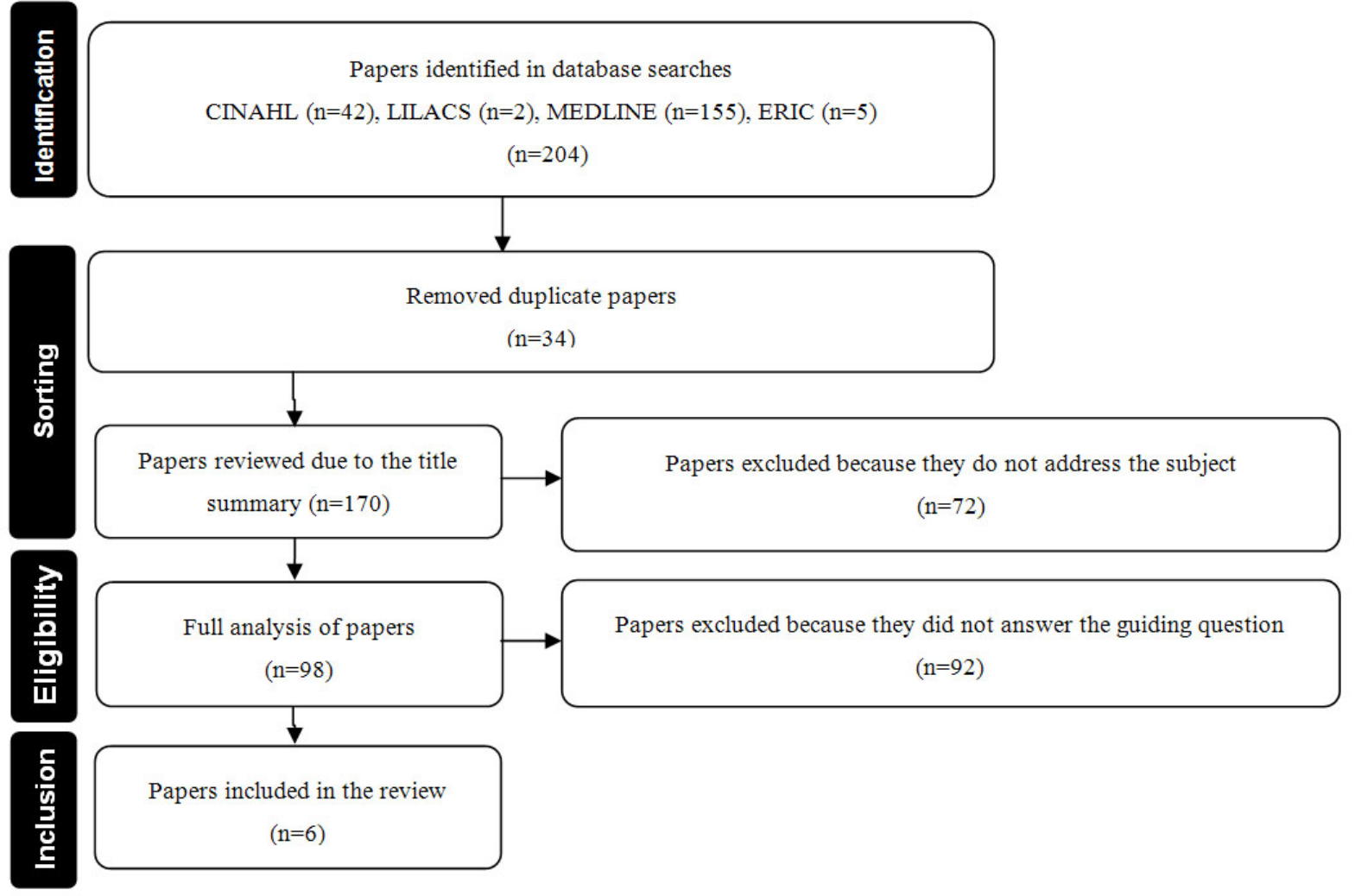

Figure 1. Flowchart showing the articles screening process. Adapted from PRISMA. ${ }^{[10]}$

A spreadsheet was developed to data collection and to help categorizing the selected articles by type of study, population/sample, country, year, title, authorship, database was rescued and journal where it was published. The articles were evaluated according to their evidence level and focused on a hierarchical classification system based on levels that go from one to six, according to the study development design. The level 1 is the strongest evidence and the level 6 is the weakest one. Level 1: evidence resulting from the meta-analysis of multiple controlled and randomized clinical studies; Level 2: evidence obtained from individual studies based on experimental design; Level 3: evidence from quasiexperimental studies; Level 4: evidence from descriptive (non-experimental) or qualitative approach studies; Level 5: evidence resulting from case or experience reports; Level 6: evidence based on experts' opinions. ${ }^{[13]}$

\section{RESUlts}

Out of the six articles included from the review it is possible to see that most of the simulation-related publications in emergency nursing education are indexed to Medline (66.6\%), and that the Nurse Education Today is the journal showing the highest frequency of articles (33.3\%). In addition, Australia and the United States are the countries showing the largest number of publications, with two publi- cations each (see Table 1). It is worth highlighting that the studies from Australia were written by the same group of authors, thus indicating the existence of a research group in simulation applied to emergency care in the country.

\subsection{Developing skills and assuredness to work in emer- gencies}

The aim of most of the studies was to analyze and/or to characterize the skills of undergraduate and graduate nursing students to work in critical situations, and the research design often used in them was the pre- and post-tests. ${ }^{[14-16]}$ Debriefing was used as the reflective exercise to discuss the performed actions in the light of the goals set for the simulation. ${ }^{[15,16]}$ Two groups of subjects were used in the samples, namely: nursing students (undergraduate and graduate) and nurses. ${ }^{[14-19]}$ Further information about the methodological approach and the aims of the articles are shown in Table 2.

\subsection{Simulation as a teaching tool}

Studies show that simulations are very well accepted as a teaching tool for professional training. ${ }^{[14-17]}$ This teaching tool allows nursing students to show better response to emergencies after they take part in simulations. ${ }^{[14-16]}$ During a simulation, it is possible for students to engage in error without consequence, that is to say without harming a live patient. ${ }^{[14-19]}$ 
Table 1. Distribution of studies according to database, title, authors, journal and study country

\begin{tabular}{|c|c|c|c|}
\hline Database/Code & Title & Authors/Year/Country & Journal (volume, $\mathbf{n}^{\circ}$, page) \\
\hline $\begin{array}{l}\text { ERIC } \\
\text { (E1) }\end{array}$ & Exploring the adoption of a virtual reality simulation & $\begin{array}{l}\text { Fagan, Kilmon, e Pandey } \\
(2012)^{[14]} \text { USA }\end{array}$ & $\begin{array}{l}\text { Campus Wide Information } \\
\text { Systems. 29(2): 117-127 }\end{array}$ \\
\hline $\begin{array}{l}\text { MEDLINE } \\
\text { (M1) }\end{array}$ & $\begin{array}{l}\text { Use of an Emergency Preparedness Disaster Simulation } \\
\text { With Undergraduate Nursing Students }\end{array}$ & $\begin{array}{l}\text { Kaplan, Connor, Ferranti, } \\
\text { Holmes, e Spencer (2011) }{ }^{[15]} \text { USA }\end{array}$ & $\begin{array}{l}\text { Public Healthing Nursing } \\
\text { 29(1): 44-51. }\end{array}$ \\
\hline $\begin{array}{l}\text { MEDLINE } \\
\text { (M2) }\end{array}$ & $\begin{array}{l}\text { Undergraduate nursing students performance in } \\
\text { recognising and responding to sudden patient } \\
\text { deterioration in high psychological fidelity simulated } \\
\text { environments: an Australian multi-centre study }\end{array}$ & $\begin{array}{l}\text { Bogossian et al. (2013) } \\
\text { Australia }\end{array}$ & $\begin{array}{l}\text { Nurse Education Today. } \\
\text { 24(5): 691-696. }\end{array}$ \\
\hline $\begin{array}{l}\text { MEDLINE } \\
\text { (M3) }\end{array}$ & $\begin{array}{l}\text { Exploring the use of standardized patients for } \\
\text { simulation-based learning in preparing advanced } \\
\text { practice nurses }\end{array}$ & $\begin{array}{l}\text { Kowitlawakul, Chow, Salam, } \\
\text { e Ignacio }(2015)^{[17]} \\
\text { Singapore }\end{array}$ & $\begin{array}{l}\text { Nurse Education Today. } \\
\text { 35(7): 894-899. }\end{array}$ \\
\hline $\begin{array}{l}\text { CINAHL } \\
\text { (C1) }\end{array}$ & $\begin{array}{l}\text { Pre-Course Simulation as a Predictor of Satisfaction with } \\
\text { an Emergency Nursing Clinical Course }\end{array}$ & $\begin{array}{l}\text { Roh e Lim }(2014)^{[18]} \\
\text { South Korea }\end{array}$ & $\begin{array}{l}\text { International Journal of } \\
\text { Nursing Education } \\
\text { Scholarship. 11(1): 1-8. }\end{array}$ \\
\hline $\begin{array}{l}\text { MEDLINE } \\
\text { (M4) }\end{array}$ & $\begin{array}{l}\text { Leadership and teamwork in medical emergencies: } \\
\text { performance of nursing students and registered nurses in } \\
\text { simulated patient scenarios }\end{array}$ & $\begin{array}{l}\text { Endacott et al. }(2015)^{[19]} \\
\text { Australia }\end{array}$ & $\begin{array}{l}\text { Journal of Clinical Nursing. } \\
\text { 24(1-2): } 90-100 .\end{array}$ \\
\hline
\end{tabular}

Table 2. Study characterization and evidence level

\begin{tabular}{|c|c|c|c|c|}
\hline Article & Aim(s) of the study & Design & Sample & Evidence level \\
\hline$(\mathrm{E} 1)^{[12]}$ & $\begin{array}{l}\text { Exploring the students' perception according to simulation } \\
\text { use }\end{array}$ & $\begin{array}{l}\text { Quantitative } \\
\text { Qualitative }\end{array}$ & $\begin{array}{l}158 \text { undergraduate } \\
\text { nursing students }\end{array}$ & Level 4 \\
\hline $\begin{array}{l}\text { Main } \\
\text { conclusions }\end{array}$ & \multicolumn{4}{|c|}{ Students confirmed the benefits of the technology used as a tool to develop better skills and behavior in a given situation. } \\
\hline$(\mathrm{M} 1)^{[13]}$ & $\begin{array}{l}\text { Describing the use of a simulation-based educational } \\
\text { strategy used to prepare nursing students to respond to } \\
\text { emergencies. }\end{array}$ & Quantitative & $\begin{array}{l}90 \text { undergraduate } \\
\text { nursing students }\end{array}$ & Level 4 \\
\hline $\begin{array}{l}\text { Main } \\
\text { conclusions }\end{array}$ & \multicolumn{4}{|c|}{$\begin{array}{l}95 \% \text { of the students strongly agreed that the simulation helps increasing their knowledge and confidence in dealing with } \\
\text { emergencies. }\end{array}$} \\
\hline$(\mathrm{M} 2)^{[14]}$ & $\begin{array}{l}\text { Identifying the clinical performance and teamwork in the } \\
\text { management of patients in critical condition. }\end{array}$ & Quantitative & $\begin{array}{l}97 \text { undergraduate } \\
\text { nursing students }\end{array}$ & Level 4 \\
\hline $\begin{array}{l}\text { Main } \\
\text { conclusions }\end{array}$ & \multicolumn{4}{|c|}{$\begin{array}{l}\text { Students showed little skill in the management of critically ill patients. Strategies such as simulation should be } \\
\text { incorporated to their curricula in order to change this context. }\end{array}$} \\
\hline$(\mathrm{M} 3)^{[15]}$ & $\begin{array}{l}\text { Exploring the students' experiences about the use of } \\
\text { simulation and identifying the learning areas that need to } \\
\text { be better addressed. }\end{array}$ & Qualitative & $\begin{array}{l}7 \text { master's students } \\
\text { in nursing }\end{array}$ & Level 4 \\
\hline $\begin{array}{l}\text { Main } \\
\text { conclusions }\end{array}$ & \multicolumn{4}{|c|}{ Students perceived that simulation is a useful and realistic tool used to develop skills and fast response to emergencies. } \\
\hline$(\mathrm{C} 1)^{[16]}$ & $\begin{array}{l}\text { The aim of the study is to determine whether pre-course } \\
\text { simulations are satisfactory for nursing students in } \\
\text { emergencies. }\end{array}$ & Quantitative & $\begin{array}{l}290 \text { undergraduate } \\
\text { nursing students }\end{array}$ & Level 4 \\
\hline $\begin{array}{l}\text { Main } \\
\text { conclusions }\end{array}$ & \multicolumn{4}{|c|}{$\begin{array}{l}\text { Simulation integration to the curricular practice is a valuable modality, which is positively evaluated in the preparation } \\
\text { of nursing students for clinical performance. }\end{array}$} \\
\hline$(\mathrm{M} 4)^{[17]}$ & $\begin{array}{l}\text { Assessing the teamwork skills used by nursing students } \\
\text { and graduate nurses to deal with critically ill patients } \\
\text { during simulation exercises involving actors playing the } \\
\text { role of patients. }\end{array}$ & $\begin{array}{l}\text { Quantitative } \\
\text { Qualitative }\end{array}$ & $\begin{array}{l}97 \text { undergraduate } \\
\text { nursing students } \\
\text { and } 44 \text { graduate } \\
\text { nurses }\end{array}$ & Level 4 \\
\hline $\begin{array}{l}\text { Main } \\
\text { conclusions }\end{array}$ & \multicolumn{4}{|c|}{$\begin{array}{l}\text { The simulation is an important tool to enable less experienced teams to develop team skills, since it provides practice } \\
\text { without putting patients at risk. }\end{array}$} \\
\hline
\end{tabular}

\subsection{Types of simulation used in emergency training}

There were only two records of low-fidelity manikin use in simulation research. However, most of the studies used

Published by Sciedu Press human patients, i.e., actors who simulated clinical symptoms or diseases in scenarios previously thought by trained researchers with clinical reasoning goals (see Table 3). ${ }^{[15-17]}$ 


\section{Discussion}

There was significant interest in analyzing the skills of nursing students to deal with emergencies through the observation of their clinical skills, critical thinking and teamwork given the complexity involving the clinical practice and the relationship with critical-condition patients. ${ }^{[14-16]}$ Nowadays, such analysis has been a very common thought since nursing students have very little contact with practical emergency situations during graduation. ${ }^{[20]}$

Table 3. Types of simulators used in emergency nursing education

\begin{tabular}{ll}
\hline Type of simulator & Studies \\
\hline High-fidelity simulator & - \\
Medium-fidelity simulator & - \\
Low-fidelity simulator & 2 (M1, C1) \\
Virtual reality & $1(\mathrm{E} 1)$ \\
Simulated patient & $4(\mathrm{M} 1, \mathrm{M} 2, \mathrm{M} 3, \mathrm{M} 4)$ \\
\hline
\end{tabular}

Nursing students are not able to recognize and to deal with emergencies; thus, they fail in the clinical management of critically ill patients. ${ }^{[14]}$ Therefore, simulations allow them to develop essential skills required to the good clinical practice such as assuredness and self-confidence. ${ }^{[1]}$

According to Oliveira, the clinical experience is essential for the development of clinical nursing practice. Thus, despite the obstacles in promoting this clinical experience (complexity of clinical and health care situations, restricted internship, etc.), alternatives such as simulations must be sought in order to allow the students to further develop their practical skills. ${ }^{[21]}$

The simulation is a training and feedback strategy, which allows students to develop and apply their knowledge and skills through the creation of conditions similar to that of the real world; thus, it helps refining the practical skills. Simulation brings students to the learning process, and it allows giving them a high degree of responsibility in a given scenario, since it would not be possible in real emergencies due to the risk to patients' life. ${ }^{[22]}$ Although high- and mediumfidelity manikins are effective in simulation scenarios, the use of actors is understandable due to the high price of the materials and the necessary expertise to operate them. ${ }^{[23]}$

Students were happy with the use of simulation, since they gained self-confidence and developed skills. The simulation allowed them to consolidate their knowledge and provided them with practical experience without the stress involved in real emergencies. According to Kowitlawakul, students recognized that simulations are extremely useful and realistic tools used to develop skills and fast response to emergencies. ${ }^{[17]}$
Whenever students cannot manage a given situation due to lack of practical and theoretical articulation, it generates many negative feelings that impair their performance and makes the situation unpleasant both for the health professional and the patient. ${ }^{[1,7]}$

The satisfaction partly comes from the contact with the practical experience, since it increases students' self-confidence to effectively and appropriately handle the emergency situation, and to provide better and safe care to the patients, thus avoiding the development of negative feelings.

Students' satisfaction with the simulation is very high, given its attractive realism and easy cognitive relation. The simulation contributes to the establishment of correct conducts, to the development of critical thinking and to the effective practice-theory correlation. ${ }^{[5,24]}$ It also contributes to the students' satisfaction because it takes them to the reality they will face in the future, and it allows critical and reflective processes in light of their actions and works as a link between the theoretical knowledge and the practical application. ${ }^{[25]}$

\section{Conclusion}

Simulation is used in emergency nursing education to evaluate the students' clinical skills and teamwork capacity. Moreover, the most used simulations are scenarios where actors play the role of patients.

The simulation used (virtual reality, simulated patient and low-fidelity simulator) proved to be an important tool to emergency nursing education, since it contributes to the professional training and to the development of clinical skills and teamwork capacity. Thus, although there is a range of manikins and simulators, the simulations involving living students mimicking signs, symptoms and responses to interventions, was the most used one. The herein analyzed studies did not use medium- or high-fidelity simulations in the emergency nursing education.

The clinical simulation proved to be a satisfactory teaching methodology with positive effects on the students' responses to emergencies involving critical contexts. The opportunity of training in a controlled environment contributes to the assuredness and to the improvement of skills; thus, it reflects on the participants' self-confidence.

Debriefing was used as a reflective exercise to guide the discussions about the goals of the simulation procedures. The incorporation of simulation to the curricular training of undergraduate nursing courses is recommended to nursing education due to its contribution to the development of clinical reasoning and to the training of skills required during emergencies. 


\section{REFERENCES}

[1] Perbone JG, Carvalho EC. Sentimentos do estudante de enfermagem em seu primeiro contato com pacientes. Revista brasileira de enfermagem. 2011; 64(2): 343-347. http://dx.doi.org/10.1590/S 0034-71672011000200019

[2] Wall P, Andrus PM, Morrison P. Bridging the theory practice gap through clinical simulation in a nursing undergraduate degree program in Australia. International Journal of Learning Teaching and Educational Research. 2014; 8(1): 127-135. Available from: http: //www.ijlter.org/index.php/ijlter/article/view/172

[3] Scully NJ. The theory-practice gap and skill acquisition: an issue for nursing education. Collegian. 2011; 18(2): 93-98. http: //dx.doi.org/10.1016/j.colegn.2010.04.002

[4] Shin S, Park J, Kim J. Effectiveness of patient simulation in nursing education: Meta-analysis. Nurse Education Today. 2015; 35(1): 176-182. http://dx.doi.org/10.1016/j.nedt.2014.09.009

[5] Baptista RC, Martins JCA, Pereira MFCR, et al. Simulation in the Nursing Degree: gains perceived by students. Revista de Enfermagem Referência. 2014; SerIV(1): 135-144. http://dx.doi.org/10. 12707 /RIII13169

[6] Martins JCA, Mazzo A, Baptista RCN, et al. The simulated clinical experience in nursing education: a historical review. Acta paulista enfermagem. 2012; 25(4): 619-625. http://dx.doi.org/10.15 90/S0103-21002012000400022

[7] Khalaila R. Simulation in nursing education: An evaluation of students' outcomes at their first clinical practice combined with simulations.Nurse Education Today. 2014; 34(2): 252-258. http: //dx.doi.org/10.1016/j.nedt.2013.08.015

[8] Shinnick MA, Woo MA. Does Nursing Student Self-efficacy Correlate with Knowledge When Using Human Patient Simulation? International Nursing Association for Clinical Simulation and Learning. 2014; 10(2): 71-79. http://dx.doi .org/10.1016/j.ecns . 2013.07.006

[9] Flato UAP, Guimarães HP. Educação baseada em simulação em medicina de urgência e emergência: a arte imita a vida. Revista Brasileira de Clinica Médica. 2011; 9(5): 360-364. http: //www.sb cm.org.br/revistas/RBCM/RBCM-2011-05.pdf

[10] Martins JCA, Baptista RCN, Coutinho VR, et al. Self-confidence for emergency intervention: adaptation and cultural validation of the Self-confidence Scale in nursing students. Revista Latino-Americana de Enfermagem. 2014; 22(4): 554-561. http://dx . doi .org/10. 1590/0104-1169.3128.2451

[11] Nascimento LKAS, Medeiros ATN, Saldanha EA, et al. Sistematização da assistência de enfermagem a pacientes oncológicos: uma revisão integrativa da literatura. Revista Gaúcha de Enfermagem. 2012; 33(1): 177-185. http://dx.doi.org/10.1590/S1983-1 4472012000100023

[12] Moher D, Liberati A, Tetzlaff J, et al. Preferred Reporting Items for Systematic Reviewa and Meta-Analyses: the PRISMA Statement. PLos Med. 2009; 6(7): e1000097. http://10.1371/journal.pm ed. 1000097

[13] Stetler CB, Morsi D, Rucki S, et al. Utilization-focused integrative reviews in a nursing service. Applied Nurse Research. 1998; 11(4): 195206. http: //dx.doi.org/10.1016/S0897-1897 (98)80329-7
[14] Fagan M, Kilmon C, Pandey V. Exploring the adoption of a virtual reality simulation. Campus-Wide Information Systems. 2012; 29(2): 117-127. http://dx.doi.org/10.1108/10650741211212368

[15] Kaplan BG, Connor A, Ferranti EP, et al. Use of an Emergency Preparedness Disaster Simulation With Undergraduate Nursing Students Public Healthing Nursing. 2011; 29(1): 44-51. http://dx.doi.o $\mathrm{rg} / 10.1111 / \mathrm{j} .1525-1446.2011 .00960 . \mathrm{x}$

[16] Bogossian F, Cooper S, Cant R, et al. Undergraduate nursing students performance in recognising and responding to sudden patient deterioration in high psychological fidelity simulated environments: an Australian multi-centre study. Nurse Education Today. 2013; 24(5): 691-696. http://dx.doi.org/10.1016/j.nedt. 2013.09.015

[17] Kowitlawakul Y, Chow YL, Salam ZHA, et al. Exploring the use of standardized patients for simulation-based learning in preparing advanced practice nurses. Nurse Education Today. 2015; 35(7): 894899. http://dx.doi.org/10.1016/j.nedt.2015.03.004

[18] Roh YS, Lim EJ. Pre-Course Simulation as a Predictor of Satisfaction with an Emergency Nursing Clinical Course. International Journal of Nursing Education Scholarship. 2014; 11(1): 1-8. http: //dx.doi.org/10.1515/ijnes-2013-0083

[19] Endacott R, Bogossian FE, Cooper SJ, et al. Leadership and teamwork in medical emergencies: performance of nursing students and registered nurses in simulated patient scenarios. Journal of Clinical Nursing. 2015; 24(1-2): 90-100. http://dx.doi.org/10.1111 /jocn. 12611

[20] Moura ECC, Caliri MHL. Simulation for the development of clinical competence in risk assessment for pressure ulcer. Acta paulista de enfermagem. 2013; 26(4): 369-375. http://dx.doi.org/10.15 90/S0103-21002013000400011

[21] Oliveira IC, Melo GSM, Costa IKF, et al. Contribuições da simulação para o processo de ensino aprendizagem da graduação em enfermagem: Revisão integrativa. Arq. Ciênc. Saúde. 2014; 21(3): 9-15. http://repositorio-racs.famerp.br/racs_o 1/vol-21-3/IDZ-575-(21-3)-jul-Se-2014.pdf

[22] Moughrabi S, Wallace DR. The effectiveness of simulation in advancing quality and safety education for nurses-based competency in accelerated nursing students. Journal of Nursing Education and Practice. 2015; 5(8): 17-25. http://dx.doi.org/10.5430/jne p.v5n8p17

[23] Gant LT. Human Simulation in Emergency Nursing Education: Current Status. Journal of Emergency Nursing. 2007; 33(1): 6971. PMid: 17258060 http://dx.doi.org/10.1016/j.jen. 200 6.09 .010

[24] Baptista RCN, Martins JCA, Pereira MFCR, et al. Alessandra. Students' satisfaction with simulated clinical experiences: validation of an assessment scale. Revista Latino-Americana de Enfermagem. 2014; 22(5): 709-715. http://dx.doi .org/10.1590/0104-116 9.3295 .2471

[25] Traynor M, Rice B, Lynn F, et al. DEVLIN Ann. A study to evaluate the introduction of simulation as a teaching strategy for the mental health and learning disability fields of nursing in an undergraduate nursing curriculum within one higher education institution in the UK. Journal of Nursing Education and Practice. 2015; 5(3): 50-58. http://dx.doi.org/10.5430/jnep.v5n3p50 